\title{
Eficiência de herbicidas aplicados em pós-emergência na cultura do feijão-caupi
}

Leandro Spíndola Pereira, Gustavo Dorneles de Sousa, Gustavo Silva de Oliveira, Jeovane Nascimento Silva, Estevam Matheus Costa, Matheus Vinicius Abadia Ventura, Adriano Jakelaitis

Instituto Federal de Educação, Ciência e Tecnologia Goiano - IF-Goiano, Campus Morrinhos, Morrinhos, GO. E-mail: adriano.jakelaitis@ifgoiano.edu.br

\section{Resumo}

Com o objetivo de avaliar a eficiência de herbicidas aplicados em pós-emergência na cultura do feijão-caupi conduziram-se dois ensaios em blocos casualizados com quatro repetições. No primeiro ensaio testaram-se a mistura comercial [bentazona + imazamoxi] associado ou não aos graminicidas haloxifope-p-metílico, fenoxaprope-p-etílico, fluazifop-p-butil, quizalofope-p-tefurílico, cletodim e tepraloxidim. E no segundo ensaio testaram-se [bentazona + imazamoxi], imazetapir, bentazona + imazetapir, etoxissulfurom + bentazona, aplicados isolados ou associados ao haloxifope-p-metílico. Foram incluídos como tratamentos as testemunhas capinadas e não capinadas. A mistura pronta de [bentazona + imazamoxi] foi seletiva ao feijoeiro cultivar BRS Guariba e promoveu controle acima de $90 \%$ de Alternanthera tenella, Commelina benghalensis e Nicandra physaloides e não controlou Eleusine indica, Cenchrus echinatus e Glycine max (soja tiguera). $O$ imazetapir associado ou não a bentazona foram seletivos à cultura do feijão-caupi, porém promoveu controle moderado ou deficiente para A. tenella, C. benghalensis, E. indica, C. echinatus e soja voluntária. A aplicação de imazetapir + bentazona apresentou controle excelente de $N$. physaloides. Foi observado $55 \%$ de fitointoxicação aos 7 dias após a aplicação (DAA) de etoxissulfuron + bentazona e recuperação parcial dos sintomas aos 28 DAA (16\%). Todavia, o feijão-caupi foi tolerante aos herbicidas etoxissulfuron + bentazona. A mistura de etoxissulfuron + bentazona promoveu controle acima de $87 \%$ para N. physaloides e de $100 \%$ para soja tiguera, mas deficiente $(<60 \%)$ para $A$. tenella, E. indica e $C$. echinatus e moderado ( $>70 \%$ ) para $C$. benghalensis. Para o controle de $E$. indica e $C$. echinatus foi necessário o uso dos graminicidas. Os rendimentos de grãos de feijão-caupi nos tratamentos com herbicidas foram semelhantes aos obtidos na testemunha capinada e superiores ao da testemunha não capinada, em ambos os ensaios. A redução de rendimento de grãos devido às plantas daninhas foi de aproximadamente $60 \%$.

Palavras-chave: comunidade infestante; fitotoxidade; Vigna unguiculata; controle químico.

\section{Efficiency of herbicides applied in post-emergency in cowpea crop}

\begin{abstract}
The objective of this work was to evaluate the efficiency of post-emergence herbicides applied to cowpea. Two trials were conducted in a randomized block with four replicates: in the first test the ready mix [bentazon + imazamox] associated or not with haloxyfop-p-methyl, phenoxaprop-p-ethyl, fluazifop-p-butyl, quizalofop-p-tefuryl, clethodim and tepraloxydim graminicides were tested. In the second trial [bentazon + imazamox], imazethapyr, bentazone + imazethapyr, ethoxysulfuron + bentazon, applied alone or associated with haloxyfop-p-methyl were tested. Non-weed and weeded controls were included as treatments. The mixture of [bentazon + imazamoxi] was selective to BRS Guariba cowpea cultivar BRS Guariba and promoted control of over $90 \%$ of Alternanthera tenella, Commelina benghalensis and Nicandra physaloides and did not control Eleusine indica, Cenchrus echinatus and Glycine max (volunteer soy plants). The imazethapyr associated or not to bentazon were selective to the cowpea, but promoted moderate or poor control for $A$. tenella, $C$. benghalensis, E. indica, C. echinatus and volunteer soy plants. The application of imazethapyr + bentazon showed excellent control of $N$. physaloides. Fifty five percent phytotoxicity was observed at 7 days after application of ethoxysulfuron + bentazon (DAA) and partial recovery of symptoms at 28 DAA (16\%). However, the cowpea was tolerant to the etoxissulfuron + bentazone herbicides. The
\end{abstract}


mixture of ethoxysulfuron + bentazon promoted control over $87 \%$ for $N$. physaloides and $100 \%$ for volunteer soy plants, but deficient $(<60 \%)$ for A. tenella, E. indica and C. echinatus and moderate $(>70 \%)$ control for $C$. benghalensis. For the control of $E$. indica and $C$. echinatus it was necessary to use the graminicides. Yields of cowpea on herbicide treatments were similar those obtained in the weed control and higher than the not weeded treatment, in both trials. The reduction of grain yield due to weeds was approximately $60 \%$.

Keywords: weed community; phytotoxicity Vigna unguiculata; chemical control.

\section{Introdução}

O feijão-caupi (Vigna unguiculata (L.) Walp), conhecido regionalmente por feijão-decorda ou feijão-macassar, é uma planta leguminosa granífera de origem africana, que se adapta bem as regiões de clima semiárido e que apresenta importância socioeconômica no Brasil (SÁ et al., 2017). A qualidade dos grãos é muito importante e benéfica para a saúde do consumidor, pois o grão apresenta alto valor nutritivo, contendo em média $56,8 \%$ de carboidratos, $1,3 \%$ de gorduras, $3,9 \%$ de fibras e 23,4\% de proteínas (OLIVEIRA et al., 2015). No Brasil, a produção da cultura concentra-se nas regiões Norte e Nordeste (CAMARA et al., 2018), e apresenta expansão acentuada para a região Centro-Oeste, principalmente Mato Grosso, sendo cultivada como segunda safra ou safrinha após a soja, ou mesmo como cultura principal (FREIRE FILHO, 2011; ZILLI et al., 2011).

Apesar de ser uma cultura tropical de ciclo curto entre 60 a 90 dias e com ampla adaptação em diversos ambientes, o feijão-caupi apresenta baixa produtividade (LEITE et al., 2009; BANDEIRA et al., 2017) em decorrência do baixo nível tecnológico associado à cultura (TEIXEIRA et al., 2010). Diversas causas são atribuídas às baixas produtividades da cultura no Brasil como déficit hídrico, manejo inadequado das práticas culturais, manejo inadequado de irrigação e interferência de plantas daninhas (MONTEIRO et al., 2017; OLIVEIRA et al., 2018). Plantas daninhas competem por recursos de crescimento, as quais afetam a lavoura diretamente por meio da competição por água, luz, e nutrientes, ou indiretamente, afetando a colheita e os processos de beneficiamento, devido à alta presença de sementes de plantas daninhas junto aos grãos da cultura (FREITAS et al., 2009; VALE et al., 2017; OLIVEIRA et al., 2018). As perdas de produtividade da cultura ocasionado pela interferência de plantas daninhas podem chegar a $90 \%$ (FREITAS et al., 2009).
Entre os métodos de manejo de plantas daninhas mais empregados na cultura do feijãocaupi destaca-se a capina manual com enxada, principalmente nas áreas de cultivos tradicionais (FREITAS et al., 2009; FONTES et al., 2017). No entanto, a capina apresenta baixo rendimento operacional quando contrastado com o controle químico. De forma geral, o uso de herbicidas proporciona redução de mão-de-obra, economia com gastos de energia e trabalho, além de permitir o controle durante o ciclo das culturas. Porém, o uso de herbicidas na cultura do feijãocaupi ainda é limitado, devido à ausência de informações sobre a seletividade dos mesmos sobre a cultura (OLIVEIRA et al., 2010; LINHARES et al., 2014; MANCUSO et al., 2016; RIBEIRO JUNIOR et al., 2018).

Embora não exista herbicidas seletivos registrados para a cultura, pesquisas apontam a possibilidade de utilização da mistura pronta de [bentazona + imazamoxi] para o controle de plantas daninhas eudicotiledôneas (SILVA et al., 2014). Da mesma forma, para o controle das plantas daninhas da família Poaceae há poucos estudos que apontem à tolerância do feijão-caupi a estes herbicidas. Simplício et al. (2016) demonstraram que o herbicida quizalofope-petílico é seletivo à cultura, enquanto Fontes et al. (2013) relataram a tolerância do feijão-caupi ao herbicida fluazifop-p-butyl aplicado em pósemergência da cultura.

O objetivo neste trabalho foi avaliar a eficiência de herbicidas aplicados em pós emergência na cultura do feijão-caupi cultivar BRS Guariba.

\section{Material e Métodos}

Dois ensaios foram instalados em 17 de março de 2018 no campo experimental do Instituto Federal de Educação Ciência e Tecnologia Goiano (IF Goiano), Campus Rio Verde, GO, sob as coordenadas geográficas $17^{\circ}$ $48^{\prime} 28.2^{\prime \prime}$ Sul e $50^{\circ} 54^{\prime}$ 09.9" Oeste e altitude de 720 metros. O clima da região é Aw mesotérmico, 
tropical de savana, pela classificação de Köppen, com chuvas distribuídas de outubro a abril e período seco nos meses de maio a setembro. A precipitação total durante a condução da pesquisa foi de $270,1 \mathrm{~mm}$.

O solo da área, classificado como Latossolo Vermelho distroférrico, apresentou na profundidade de 0 a $20 \mathrm{~cm}$, a seguinte composição físico-química: pH 6,2 (SMP), Ca de 4,64 $\mathrm{cmol}_{\mathrm{c}} \mathrm{dm}^{-3}, \mathrm{Mg}$ de 2,50 $\mathrm{cmol}_{\mathrm{c}} \mathrm{dm}^{-3}, \mathrm{Al}^{3+}$ de $0,04 \mathrm{cmol}_{\mathrm{c}} \mathrm{dm}^{-3}, \mathrm{H}+\mathrm{Al}$ de $4,5 \mathrm{cmol}_{\mathrm{c}} \mathrm{dm}^{-3}$, CTC de $12,1 \mathrm{cmol}_{c} \mathrm{dm}^{-3}$ e $\mathrm{K}$ de $0,46 \mathrm{cmol}_{c} \mathrm{dm}^{-3}$ e $\mathrm{P}$ (Melich) de 13,1 mg dm${ }^{-3}$, matéria orgânica de 3,62 $\mathrm{mg} \mathrm{dm}^{-3}$ e $\mathrm{Zn} \mathrm{4,5} \mathrm{mg} \mathrm{dm}{ }^{-3}$, saturação por bases de $62,8 \%$, saturação por alumínio de $0,5 \%$, argila de $64,5 \%$, silte $10,0 \%$ e areia de $25,5 \%$.

Antes da instalação dos ensaios, a vegetação de plantas daninhas da área foi dessecada com glifosato na dose de 1.440 g e.a. $\mathrm{ha}^{-1}$. Quinze dias após realizou-se a semeadura direta das sementes de feijão-caupi cultivar BRS Guariba, de porte semi-ereto e grãos brancos. As sementes foram inoculadas com Bradyrhizobium spp. e tratadas com Standak Top ${ }^{\circledR}$ [fipronil $(250 \mathrm{~g}$ $\left.\mathrm{L}^{-1}\right)+$ piraclostrobina $25\left(\mathrm{~g} \mathrm{~L}^{-1}\right)+$ tiofanato-metílico $\left.225\left(\mathrm{~g} \mathrm{~L}^{-1}\right)\right]$ na dose de $200 \mathrm{~mL}$ do produto comercial para $100 \mathrm{~kg}$ de sementes. A adubação de semeadura foi de $300 \mathrm{~kg} \mathrm{ha}^{-1}$ da formulação 04-14-08.

O delineamento experimental utilizado em ambos os ensaios foi o de blocos casualizados completos, com quatro repetições. Cada unidade experimental foi composta por cinco linhas de feijão-caupi, espaçadas a $0,45 \mathrm{~m}$, com sete metros de comprimento totalizando $15,75 \mathrm{~m}^{2}$. A descrição dos tratamentos encontra-se na Tabela 1.

A emergência das plântulas ocorreu em 25 de março de 2018, e aos 13 e 17 dias após a emergência (DAE), 07/04/2018 e 11/04/2018, foram aplicados os tratamentos dos experimentos 1 e 2, respectivamente, com pulverizador pressurizado por $\mathrm{CO}_{2}$, equipado com barra de quatro pontas TT 11002, espaçadas de $0,50 \mathrm{~m}$, posicionados a $0,5 \mathrm{~m}$ de altura em relação à superfície das plantas, volume de calda de $200 \mathrm{~L} \mathrm{ha}^{-1}$ e pressão de trabalho de 2,5 bar. Os herbicidas inibidores da Acetilcoenzima A carboxilase (ACCase) (haloxifope-p-metílico, fenoxaprope-p-etílico, fluazifop-p-butil, quizalofope-p-tefurílico, cletodim e tepraloxidim) foram aplicados aos cinco dias após a aplicação dos demais herbicidas que constituíram tratamentos, para evitar antagonismo (Tabela 1). 
Tabela 1. Herbicidas, doses e produtos comerciais dos herbicidas aplicados em pós-emergência na cultura do feijão-caupi, em ambos os experimentos

\begin{tabular}{|c|c|c|}
\hline Tratamentos (Ensaio 1) & Dose $\left(\mathrm{g} \mathrm{ha}^{-1}\right)$ & Produto comercial \\
\hline Testemunha capinada & - & - \\
\hline Testemunha não capinada & - & - \\
\hline 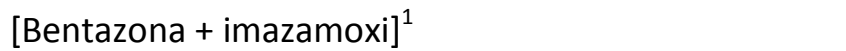 & $600+28$ & Amplo \\
\hline 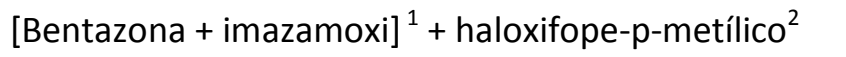 & $(600+28 g)+62,35 g$ & Amplo + Verdict $R$ \\
\hline 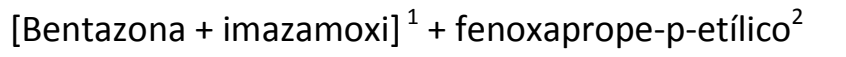 & $(600+28 g)+82,5 g$ & Amplo + Podium EW \\
\hline 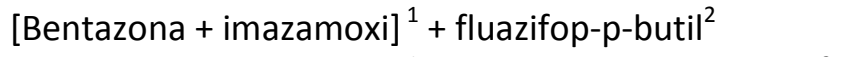 & $(600+28 g)+187,5 g$ & Amplo + Fusilade $250 \mathrm{EW}$ \\
\hline 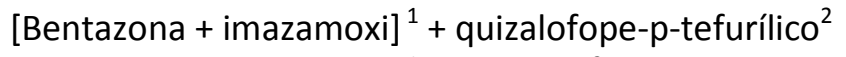 & $(600+28 g)+72 g$ & Amplo + Panther 120 EC \\
\hline 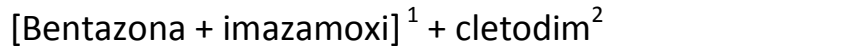 & $(600+28 g)+108 g$ & Amplo + Select 240 EC \\
\hline 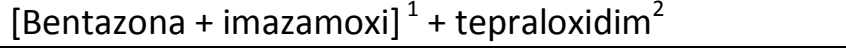 & $(600+28 g)+100 g$ & Amplo + Aramo 200 \\
\hline Tratamentos (Ensaio 2) & Dose & Produto comercial \\
\hline Testemunha capinada & - & - \\
\hline Testemunha não capinada & - & - \\
\hline [Bentazona + imazamoxi] $^{1}$ & $600+28 g$ & Amplo \\
\hline 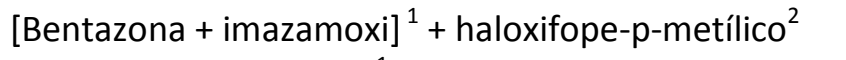 & $(600+28 g)+62,35 g$ & Amplo + Verdict $\mathrm{R}$ \\
\hline Bentazona + imazetapir ${ }^{1}$ & $(720+42,4 g)$ & Basagran $600+$ Vezir 100 \\
\hline Bentazona + imazetapir ${ }^{1}+$ haloxifope-p-metílico ${ }^{2}$ & $(720+42,4 g)+62,35 g$ & Basagran $600+$ Vezir $100+$ Verdict $R$ \\
\hline Imazetapir ${ }^{1}$ & $42,4 \mathrm{~g}$ & Vezir 100 \\
\hline Imazetapir ${ }^{1}+$ haloxifope-p-metílico ${ }^{2}$ & $(42,4 g)+62,35 g$ & Vezir $100+$ Verdict $R$ \\
\hline Etoxissulfurom + bentazona & $24 g+720 g$ & Gladium + Basagran 600 \\
\hline 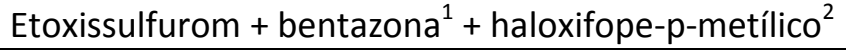 & $(24 g+720 g)+62,35 g$ & Gladium + Basagran 600 + Verdict R \\
\hline
\end{tabular}


Todas as aplicações, de ambos os ensaios e as sequenciais com inibidores da ACCase, foram realizadas no período matutino, entre 7:00h e 9:30h, com temperatura do ar entre 26,3 a $27,7^{\circ} \mathrm{C}$; umidade relativa do ar entre 67,4 a $74,2 \%$, velocidade do vento inferior a $1,0 \mathrm{~m} \mathrm{~s}^{-1}$, e solo úmido à superfície. As parcelas adjacentes foram protegidas no momento da aplicação com lona plástica para evitar à deriva. Na testemunha capinada, de ambos os ensaios, as parcelas foram mantidas sem convivência de plantas daninhas por meio de capinas manuais semanais até o final do ciclo da cultura. Não foram realizados tratamentos fitossanitários com fungicidas ou inseticidas ou aplicação de adubação de cobertura na cultura.

Aos 7 e 28 dias após a aplicação (DAA) dos herbicidas foi avaliada a porcentagem de fitointoxicação da cultura (SBCPD, 1995) e das plantas daninhas predominantes (Alternanthera tenella, Commelina benghalensis, Cenchrus echinatus, Nicandra physalodes e Eleusine indica) por meio de escala percentual de notas de 0 a $100 \%$, em que zero representou ausência de injúrias nas plantas e cem à morte das mesmas (ALAM, 1974). Aos 28 DAA, foi realizado o levantamento de plantas daninhas, por meio do lançamento ao acaso de dois quadrados amostrais, vazados, de $0,16 \mathrm{~m}^{2}$ por parcela. As plantas daninhas identificadas foram coletadas, separadas, acondicionadas em saquinhos de papel e conduzidas à estufa de renovação e circulação forçada de ar a 65 ㅇ por 72 horas, até atingir massa constante, sendo posteriormente, pesadas.

No florescimento da cultura (46 DAE) foram colhidas duas plantas, por parcela, as quais foram cortadas rentes ao solo, e conduzidas ao laboratório, para determinação da altura de plantas (AP), diâmetro da haste (DH) e área foliar $(\mathrm{AF})$. Para determinação da AP utilizou régua graduada, medindo da base até o meristema apical da planta, e com auxílio de paquímetro digital, aferiu-se o DH. Foram mensuradas o comprimento (C) e de largura (L) das folhas de ambas as plantas com auxílio de régua e a $A F$ foi obtida indiretamente por meio do produto das medidas de $\mathrm{C}$ e $\mathrm{L}$ por meio da equação: $\mathrm{AF}=$ $\Sigma(0,6597(\mathrm{C} \times \mathrm{L})+2,1745)$ (SOUZA LIMA et al., 2008).

Aos 85 DAE quando os feijoeiros atingiram à maturidade fisiológica foi realizado a dessecação química em pré-colheita das plantas com auxílio de pulverizador motorizado, aplicando-se $400 \mathrm{~g} \mathrm{ha}^{-1}$ de paraquat
(Gramoxone ${ }^{\circledR} 200$ ) e volume de calda de $200 \mathrm{~L}$ ha ${ }^{1}$. Aos 95 DAE foram colhidos dez feijoeiros da área útil da parcela para estimar o número de vagens (NVP) e de grãos por planta (NGP) e a massa de mil grãos (MCG). Das duas linhas centrais da parcela, de comprimento de cinco metros, as plantas foram contadas, colhidas e trilhadas para obtenção da população final (PF) e do rendimento de grãos (RG), a 13\% de umidade, em base úmida.

Os resultados foram submetidos à análise de variância, e quando significativos, as médias foram contrastadas pelo teste de Scott Knott, a $5 \%$ de probabilidade, por meio do software Sisvar versão 5.6.

\section{Resultados e Discussão}

Nas Tabelas 2 e 3 são apresentadas as porcentagens de fitointoxicação da cultura e o controle das plantas daninhas que ocorreram nos ensaios 1 e 2 . As fitointoxicações dos feijoeiros avaliadas no ensaio 1 foram caracterizadas por sintomas leves promovidos pela mistura pronta de [bentazona + imazamoxi] e da aplicação sequenciada destes com os inibidores da ACCase (haloxifope-p-metílico, fluazifop-p-butil, quizalofope-p-tefurílico, cletodim e tepraloxidim), atingindo valores abaixo de $5,0 \%$ aos 7 DAA (Tabela 2). Menor valor foi observado aos 7 DAA para a combinação [bentazona + imazamoxi] + fenoxaprope-p-etílico com $1 \%$ de fitointoxicação. 
Tabela 2. Fitointoxicação (FI) do feijoeiro e controle das plantas daninhas Alternanthera tenella (ALTTE), Commelina benghalensis (COMBE), Cenchrus echinatus (CENEH), Eleusine indica (ELEIB) e Nicandra physaloides (NICPH) aos 7 e 28 dias após a aplicação (DAA) dos herbicidas (Ensaio 1)

\begin{tabular}{|c|c|c|c|c|c|c|c|c|c|c|c|c|}
\hline \multirow{3}{*}{ Tratamentos } & \multicolumn{2}{|c|}{$\mathrm{FI}$} & \multicolumn{2}{|c|}{ ALTTE } & \multicolumn{2}{|c|}{ COMBE } & \multicolumn{2}{|c|}{ CENEH } & \multicolumn{2}{|c|}{ ELEIN } & \multicolumn{2}{|c|}{$\mathrm{NICPH}$} \\
\hline & 7 & 28 & 7 & 28 & 7 & 28 & 7 & 28 & 7 & 28 & 7 & 28 \\
\hline & \multicolumn{12}{|c|}{ DAA - dias após a aplicação } \\
\hline [Bentazona + imazamoxi] $^{1}$ & $3 \mathrm{~b}$ & 0 & $88 \mathrm{a}$ & 100 & $46 \mathrm{a}$ & $100 \mathrm{a}$ & $43 \mathrm{a}$ & $20 \mathrm{~b}$ & $8 \mathrm{~b}$ & $12 \mathrm{~b}$ & 100 & 100 \\
\hline [Bentazona + imazamoxi] $^{1}+$ haloxifope-p-metílico $^{2}$ & $5 b$ & 0 & $81 \mathrm{a}$ & 100 & $47 \mathrm{a}$ & 97 a & $46 \mathrm{a}$ & $100 \mathrm{a}$ & $4 a$ & $100 \mathrm{a}$ & 100 & 100 \\
\hline 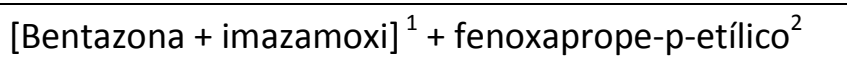 & $1 \mathrm{a}$ & 0 & $81 \mathrm{a}$ & 100 & $50 \mathrm{a}$ & $97 \mathrm{a}$ & $41 \mathrm{a}$ & $100 \mathrm{a}$ & $8 \mathrm{~b}$ & $100 \mathrm{a}$ & 100 & 100 \\
\hline [Bentazona + imazamoxi] $^{1}+$ fluazifop-p-butil $^{2}$ & $4 \mathrm{~b}$ & 0 & $87 a$ & 100 & $52 \mathrm{a}$ & 97 a & 48 a & $100 \mathrm{a}$ & $7 \mathrm{~b}$ & $100 \mathrm{a}$ & 100 & 100 \\
\hline 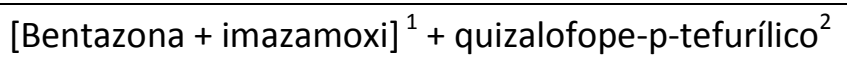 & $5 \mathrm{~b}$ & 0 & $83 \mathrm{a}$ & 100 & $52 \mathrm{a}$ & $98 \mathrm{a}$ & $46 \mathrm{a}$ & $100 \mathrm{a}$ & $9 \mathrm{~b}$ & $100 \mathrm{a}$ & 100 & 100 \\
\hline 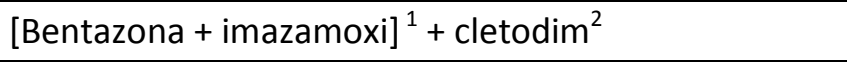 & $3 \mathrm{~b}$ & 0 & $85 \mathrm{a}$ & 100 & $53 \mathrm{a}$ & $100 \mathrm{a}$ & $57 \mathrm{a}$ & $100 \mathrm{a}$ & $13 \mathrm{a}$ & $100 \mathrm{a}$ & 100 & 100 \\
\hline 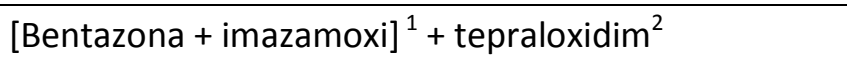 & $3 \mathrm{~b}$ & 0 & $86 \mathrm{a}$ & 100 & $58 \mathrm{a}$ & $100 \mathrm{a}$ & $31 \mathrm{a}$ & $100 \mathrm{a}$ & $2 \mathrm{~b}$ & $100 \mathrm{a}$ & 100 & 100 \\
\hline CV (\%) & 15,31 & - & 5,52 & - & 21,21 & 3,48 & 19,61 & 3,48 & 17,95 & 2,16 & - & - \\
\hline
\end{tabular}

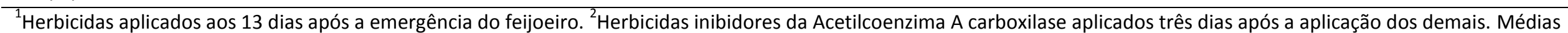
seguidas pelas mesmas letras são estatisticamente iguais pelo teste de $\operatorname{Scott}-\operatorname{Knott}(p<0,05)$. 
Tabela 3. Fitointoxicação (FI) do feijoeiro e controle das plantas daninhas Alternanthera tenella (ALTTE), Commelina benghalensis (COMBE), Cenchrus echinatus (CENEH), Eleusine indica (ELEIB), Nicandra physalodes (NICPH) e Glycine max (GLYMA) aos 7 e 28 dias após a aplicação (DAA) dos herbicidas (Ensaio 2)

\begin{tabular}{|c|c|c|c|c|c|c|c|c|c|c|c|c|c|c|}
\hline \multirow{3}{*}{ Tratamentos } & \multicolumn{2}{|c|}{$\mathrm{FI}$} & \multicolumn{2}{|c|}{ ALTTE } & \multicolumn{2}{|c|}{ COMBE } & \multicolumn{2}{|c|}{ CENEH } & \multicolumn{2}{|c|}{ ELEIN } & \multicolumn{2}{|c|}{$\mathrm{NICPH}$} & \multicolumn{2}{|c|}{ GLYMA } \\
\hline & 7 & 28 & 7 & 28 & 7 & 28 & 7 & 28 & 7 & 28 & 7 & 28 & 7 & 28 \\
\hline & \multicolumn{14}{|c|}{ DAA - dias após a aplicação } \\
\hline [Bentazona + imazamoxi] $^{1}$ & $1 \mathrm{a}$ & $0 \mathrm{a}$ & $90 \mathrm{a}$ & $100 \mathrm{a}$ & $57 \mathrm{a}$ & $100 \mathrm{a}$ & $18 \mathrm{~b}$ & $17 \mathrm{c}$ & $5 \mathrm{~b}$ & $20 \mathrm{~b}$ & $100 \mathrm{a}$ & 100 & $\mathrm{Ob}$ & $0 \mathrm{a}$ \\
\hline 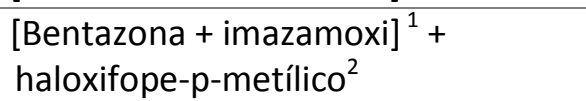 & $0 \mathrm{a}$ & $0 \mathrm{a}$ & 90 a & $100 \mathrm{a}$ & 55 a & $100 \mathrm{a}$ & $32 \mathrm{a}$ & $100 \mathrm{a}$ & $12 \mathrm{a}$ & $100 \mathrm{a}$ & $100 \mathrm{a}$ & 100 & $0 \mathrm{~b}$ & $0 \mathrm{a}$ \\
\hline Bentazona + imazetapir ${ }^{1}$ & $0 \mathrm{a}$ & $0 \mathrm{a}$ & $65 \mathrm{~b}$ & $70 \mathrm{~b}$ & $43 a$ & $85 b$ & $17 \mathrm{~b}$ & $15 \mathrm{c}$ & $2 \mathrm{~b}$ & $15 \mathrm{~b}$ & $100 \mathrm{a}$ & $100 \mathrm{a}$ & $\mathrm{Ob}$ & $0 \mathrm{a}$ \\
\hline $\begin{array}{l}\text { Bentazona + imazetapir }{ }^{1}+ \\
\text { haloxifope-p-metílico }^{2}\end{array}$ & $0 \mathrm{a}$ & $0 \mathrm{a}$ & $63 \mathrm{~b}$ & $65 \mathrm{~b}$ & $42 \mathrm{a}$ & $77 \mathrm{~b}$ & $25 \mathrm{a}$ & $100 \mathrm{a}$ & $11 \mathrm{a}$ & $100 \mathrm{a}$ & $100 \mathrm{a}$ & $100 \mathrm{a}$ & $0 \mathrm{~b}$ & $0 \mathrm{a}$ \\
\hline Imazetapir $^{1}$ & $1 \mathrm{a}$ & $0 \mathrm{a}$ & $46 \mathrm{c}$ & $52 \mathrm{~b}$ & $47 a$ & $60 c$ & $12 \mathrm{~b}$ & $35 \mathrm{~b}$ & $2 \mathrm{~b}$ & $22 \mathrm{~b}$ & $45 \mathrm{~b}$ & $72 \mathrm{~b}$ & $\mathrm{Ob}$ & $0 \mathrm{a}$ \\
\hline Imazetapir $^{1}+$ haloxifope-p-metílico ${ }^{2}$ & $3 a$ & $0 \mathrm{a}$ & $47 \mathrm{c}$ & $60 \mathrm{~b}$ & $45 a$ & $62 c$ & $28 a$ & $100 \mathrm{a}$ & $12 \mathrm{a}$ & $100 \mathrm{a}$ & $45 \mathrm{~b}$ & $77 \mathrm{~b}$ & $\mathrm{Ob}$ & $0 \mathrm{a}$ \\
\hline Etoxissulfurom + bentazona ${ }^{1}$ & $55 \mathrm{~b}$ & $16 \mathrm{~b}$ & $72 \mathrm{~b}$ & $22 \mathrm{c}$ & $45 a$ & $71 \mathrm{~b}$ & $1 \mathrm{c}$ & $5 \mathrm{c}$ & $0 \mathrm{~b}$ & $5 c$ & $100 \mathrm{a}$ & $100 \mathrm{a}$ & 90 a & $100 \mathrm{~b}$ \\
\hline $\begin{array}{l}\text { Etoxissulfurom + bentazona }{ }^{1}+ \\
\text { haloxifope-p-metílico }^{2}\end{array}$ & $56 \mathrm{~b}$ & $16 \mathrm{~b}$ & $72 \mathrm{~b}$ & $16 \mathrm{c}$ & $40 \mathrm{a}$ & $71 b$ & $27 \mathrm{a}$ & $100 \mathrm{a}$ & $10 \mathrm{a}$ & $100 \mathrm{a}$ & $100 \mathrm{a}$ & $100 \mathrm{a}$ & $87 a$ & $100 \mathrm{~b}$ \\
\hline CV (\%) & 14,84 & 19,27 & 14,43 & 18,82 & 25,36 & 11,25 & 18,98 & 13,65 & 29,88 & 13,02 & 19,84 & 9,43 & 18,81 & - \\
\hline
\end{tabular}

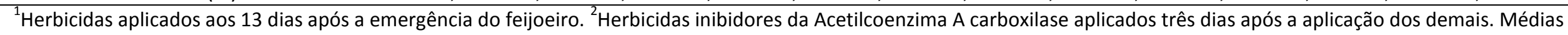
seguidas pelas mesmas letras são estatisticamente iguais pelo teste de Kcott-knott $(p<0,05)$ 
As combinações de herbicidas usados no ensaio 1 demonstraram seletividade ao feijãocaupi cV. BRS Guariba em decorrência do desaparecimento dos sintomas nas plantas aos 28 DAA (Tabela 1). Resultados similares foram observados por Linhares et al. (2014), onde os herbicidas [bentazona + imazamoxi] causaram leve amarelecimento das folhas aos 3 DAA, com total recuperação aos 15 DAA, quando aplicados neste mesmo cultivar. Todavia, Bandeira et al. (2017) avaliando a seletividade de herbicidas no feijão-caupi cultivar BRS Aracê verificaram que a mistura [bentazona + imazamoxi] causou intoxicação de $48,75 \%$ aos 3 DAA, com folhas que exibiram redução da espessura foliar e posterior queda; porém, os feijoeiros apresentaram recuperação com fitointoxicação de $18,0 \%$ aos 21 DAA.

O herbicida imazetapir e a sua mistura com bentazona aplicados no ensaio 2 (Tabela 3 ) foram seletivos para o feijão-caupi cv. BRS Guariba, apresentando sintomas leves aos 7 DAA e ausência de fitointoxicação aos 28 DAA, mesmo quando combinado com haloxifope-p-metílico, aplicado sequencialmente (Tabela 3). Por outro lado, a mistura de tanque de etoxissulfurom + bentazona promoveu fitointoxicação média (55\%) nas plantas de feijão-caupi aos 7 DAA com recuperação parcial (16\%) aos 28 DAA. Nos tratamentos com aplicação dos herbicidas inibidores da ACCase, específico para o controle de plantas daninhas gramíneas (SILVA et al., 2014), não se observaram sintomas de intoxicação do feijão-caupi (Tabelas 2 e 3), o que demonstra a seletividade desses herbicidas para a cultura. Deste modo, pode-se inferir que a intoxicação do feijão-caupi com o uso do haloxifope-p-metílico foi causada pela mistura com etoxissulfurom (Tabela 3 ).

A comunidade de plantas daninhas em ambos os ensaios foi composta por 25 espécies, distribuídas em 9 famílias. As famílias que se destacaram foi a Asteraceae com as espécies Emilia fosbergii (falsa-serralha), Synedrellopsis grisebachii (agriãozinho), Acanthospermum hispidum (carrapicho-de-carneiro), Ageratum conyzoides (mentrasto), Bidens pilosa (picãopreto), e Conyza bonariensis e Conyza canadensis (buva); seguida por Poaceae: Panicum maximum (capim-colonião), Cenchrus echinatus (capimcarrapicho), Digitaria insularis (capim-amargoso)

e Eleusine indica (capim-pé-de-galinha); Amaranthaceae: Alternanthera tenella (apagafogo), Amaranthus hybridus (caruru-roxo) e Amaranthus viridis (caruru-de-mancha);
Euphorbiaceae: Ricinus communis (mamona) e Chamaesyce hirta (erva-de-santa-luzia); Fabaceae: Glycine max (soja voluntária) e Desmodium tortuosum (desmódio); Commelinaceae: Commelina benghalensis (trapoeraba); Papaveraceae: Argemone mexicana (papoula-do-méxico); Solanaceae: Nicandra physaloides (joá-de-capote); e Portulacaceae: Portulaca oleraceae (beldroega). As espécies dominantes foram Alternanthera tenella, Commelina benghalensis, Cenchrus echinatus, Eleusine indica e Nicandra physaloides (ensaios 1 e 2) e a soja voluntária (Glycine $\max$ ) no ensaio 2.

O nível de controle de plantas daninhas no ensaio 1 avaliado aos 7 DAA foi acima de 80\% (bom) para A. tenella e $N$. physaloides para a mistura de [bentazona + imazamoxi] associado ou não aos graminicidas e acima de $95 \%$ (excelente) aos 28 DAA, exceto para a mistura pronta [bentazona + imazamoxi] no controle de $C$. echinatus e $E$. indica, que situou-se entre 12 a $20 \%$, sendo considerado deficiente (Tabela 2 ). Plantas daninhas quando não controladas podem diminuir o estande da cultura, o número de vagens por planta e o rendimento de grãos da cultura do feijão-caupi entre 46 (CORREA et al., 2015) a 90\% (FREITAS et al., 2009), se comparado a cultura cultivada livre de interferência. $O$ uso da associação de herbicidas bentazona + imazamoxi com ou sem graminicidas aplicados no feijãocaupi promoveu redução da densidade e da massa seca de plantas daninhas aos 28 DAA com controle semelhante aos obtidos nas parcelas capinadas (Figura 1A e 1B).

No ensaio 2, aos 7 DAA, foram considerados controle excelente (acima de $90 \%$ ) os promovidos por [bentazona + imazamoxi] associado ou não ao haloxifope-p-metílico para $A$. tenella e $N$. physaloides e por bentazona + imazetapir associado ou não ao haloxifope-pmetílico para $N$. physaloides e etoxissulfurom + bentazona associado ou não ao haloxifope-pmetílico para $N$. physaloides e plantas voluntárias de soja (Tabela 3 ), sendo os demais tratamentos considerados moderados ou deficientes. Aos 28 DAA, foi observado controle excelente (100\%) para A. tenella, C. benghalensis e N. physaloides para a mistura pronta de [bentazona + imazamoxi], e quando associado ao haloxifope-pmetílico demonstrou também controle excelente para $E$. indica e $C$. echinatus. Esta associação de herbicidas ([bentazona + imazamoxi] + haloxifope-p-metílico) demonstrou-se segura ao cultivar BRS Guariba e eficaz no controle de plantas daninhas, com redução de $90 \%$ da 
densidade e $95 \%$ da massa seca acumulada pela comunidade infestante, se comparada as parcelas não capinadas (Figura 2A e 2B). Estes resultados concordam com os observados por Silva et al. (2014) que verificaram aos 28 dias após a semeadura controle excelente $(100 \%)$ para as plantas daninhas Cleome affinis, Amaranthus spinosus, Digitaria bicornis e Commelina benghalensis e seletividade para o cultivar BRS Guariba, quando tratado com [bentazona + imazamoxi] + fluazifop-p-butil.

Figura 1. Densidade (A) e massa seca (B) de plantas daninhas avaliadas aos 28 DAA em função da aplicação de herbicidas em pós emergência do feijoeiro (Ensaio 1 ).

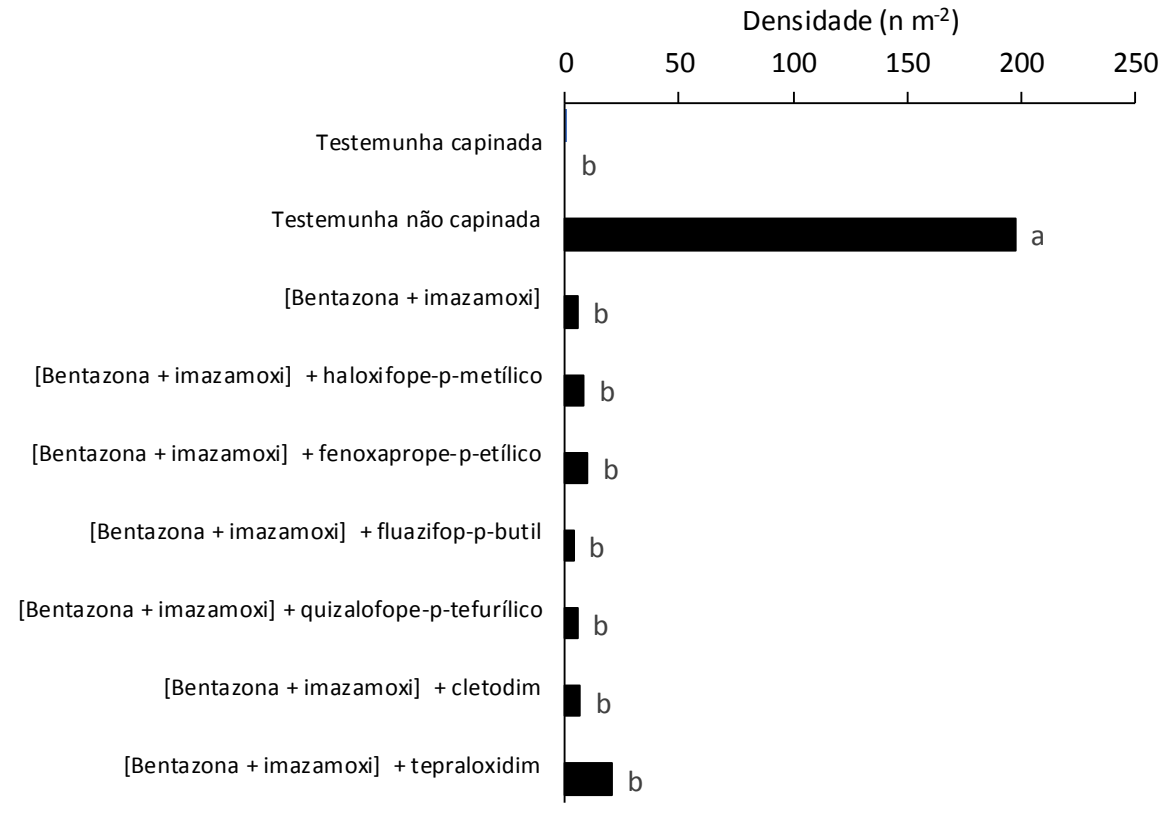

(A)

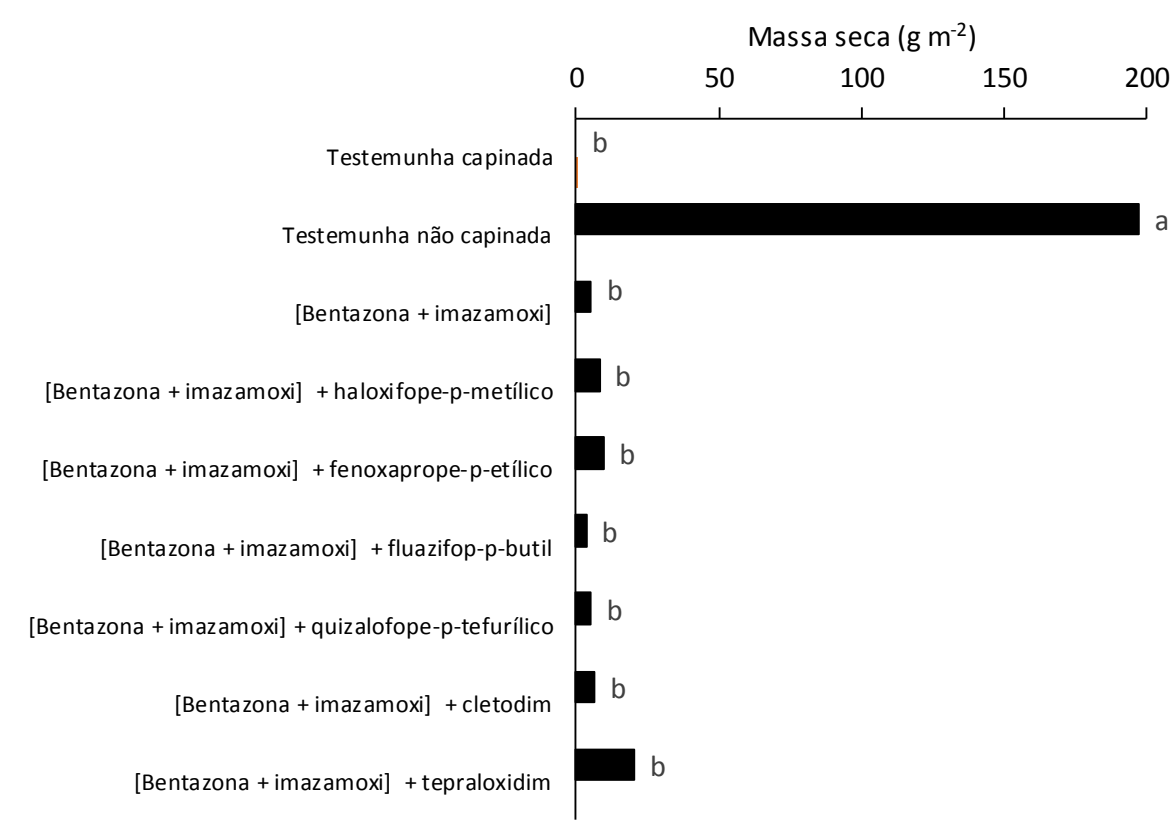

(B)

Aos 28 DAA a aplicação de imazetapir promoveu controle moderado $(60-79 \%)$ para $N$. physaloides e $C$. benghalensis e deficiente $(<60 \%)$ para $A$. tenella, soja tiguera, C. echinatus e $E$. indica (Tabela 3). Associado a bentazona promoveu bom controle (80-89\%) de $C$. benghalensis e excelente para $N$. physaloides e deficiente (<60\%) para $A$. tenella, soja tiguera, $C$. 
echinatus e E. indica. Controle excelente destes herbicidas sobre $E$. indica e $C$. echinatus ocorreu quando da associação com haloxifope-p-metílico. Todavia, mesmo com controle parcial da comunidade infestante pelo imazetapir, imazetapir + bentazon, imazetapir + bentazona + haloxifope-p-metílico a redução da densidade de infestação e da massa seca acumulada aos 28 DAA, assemelham-se ao tratamento mantido por capinas (Figura 2A e 2B).

A mistura de etoxissulfurom + bentazona foram eficientes no controle de soja voluntária e $N$. physaloides e quando associados ao haloxifope-p-metílico promoveu também o controle das gramíneas $C$. echinatus e $E$. indica (Tabela 3). O controle da soja tiguera na cultura do feijão-caupi deveu-se a presença do herbicida etoxissulfurom, corroborando com os resultados obtidos por Assis et al. (2014), que confirmaram a seletividade para o feijoeiro-comum (Phaseolus vulgaris) e o controle da soja. Todavia, o controle inexpressivo da mistura etoxissulfurom + bentazona para $A$. tenella, $C$. echinatus e $E$. indica e moderado para $C$. benghalensis resultou em acúmulo massa seca acumulada da comunidade infestante semelhante à observada na testemunha não capinada (Figuras 2A e 2B).

Na Tabela 4 são apresentadas as variáveis mensuradas no florescimento e na colheita da cultura do feijão-caupi. O DH, NVP e MMG em ambos os ensaios e o NGP no ensaio 1 não foram afetados pelos tratamentos. Os feijoeiros com menores AP foram observados nas parcelas não capinadas em ambos os ensaios em função da interferência de plantas daninhas e também nas parcelas tratadas com a mistura pronta de [bentazona + imazamoxi] ou associado com fluazifop-p-butil, ou quizalofope-p-tefurílico, ou cletodim no ensaio 1 (Tabela 4). No ensaio 2 foi observado, além da testemunha não capinada, feijoeiros de menor porte nas parcelas tratadas com etoxissulfurom + bentazona associado ou não ao haloxifope-p-metílico, sendo que este efeito pode estar associado à fitotoxicidade e ao controle parcial de plantas daninhas (Tabela 3 e Figura 2B).

Em relação as variáveis que afetam o rendimento de grãos do feijão-caupi cujos valores foram menores do que as testemunhas capinadas foram a AF para a aplicações de imazetapir + haloxifope-p-metílico e de etoxissulfurom + bentazona + haloxifope-p-metílico no ensaio 2 , a PF para a aplicação de [bentazona + imazamoxi] + haloxifope-p-metílico no ensaio 1 e o NGP para aplicações de imazetapir e de etoxissulfurom + bentazona associado ou não ao haloxifope-pmetílico ${ }^{2}$ no ensaio 2 , além das testemunhas não capinadas (Tabela 4). Apesar dos menores valores de algumas variáveis avaliadas no florescimento e na colheita do feijoeiro em função de tratamentos com herbicidas foram verificados somente nas parcelas não capinadas menor RG do feijão-caupi em relação aos tratamentos capinados ou tratados com herbicidas (Tabela 4). 
Figura 2. Densidade (A) e massa seca (B) de plantas daninhas avaliadas aos 28 DAA em função da aplicação de herbicidas em pós emergência do feijoeiro (Ensaio 2).

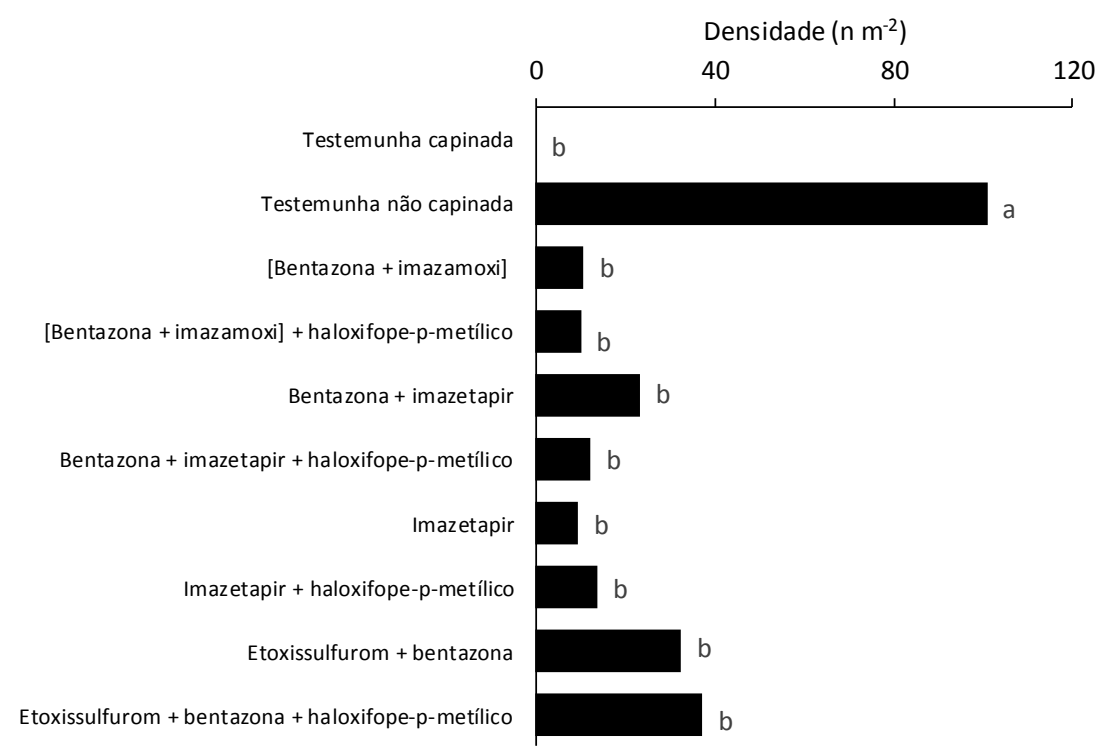

(A)

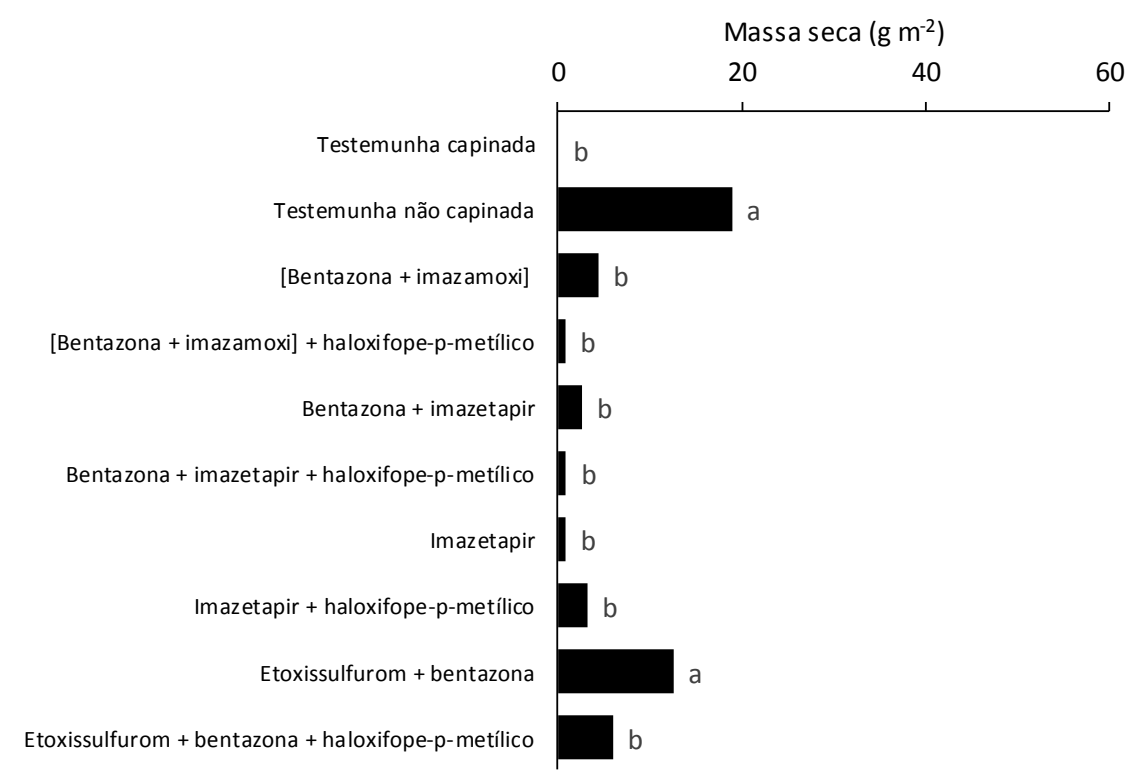

(B) 
Tabela 4. População final de plantas (PF), número de vagens por planta (NVP), número de grãos por planta (NGP), massa de mil grãos (MMG) e rendimento de grãos (RG) de feijão-caupi após a aplicação de herbicidas em pós emergência

\begin{tabular}{|c|c|c|c|c|c|c|c|c|}
\hline \multicolumn{9}{|c|}{ Ensaio 1} \\
\hline Tratamentos & $\mathrm{AP}(\mathrm{cm})$ & $\mathrm{DH}(\mathrm{mm})$ & $\mathrm{AF}\left(\mathrm{cm}^{2}\right)$ & $\mathrm{PF}\left(\mathrm{n} \mathrm{ha} \mathrm{a}^{-1}\right)$ & NVP & NGP & MMG (g) & $\mathrm{RG}\left(\mathrm{kg} \mathrm{ha}^{-1}\right)$ \\
\hline Testemunha capinada & $51,8 a^{1}$ & $6,63 \mathrm{a}$ & $92,56 \mathrm{a}$ & $155.000 \mathrm{a}$ & $7,2 \mathrm{a}$ & $45,2 \mathrm{a}$ & $201,0 \mathrm{a}$ & 932,73 a \\
\hline Testemunha não capinada & $43,9 \mathrm{~b}$ & $6,16 \mathrm{a}$ & $76,60 \mathrm{~b}$ & $105.333 \mathrm{~b}$ & 5,4 a & 29,6 a & 195,8 a & $381,63 \mathrm{~b}$ \\
\hline 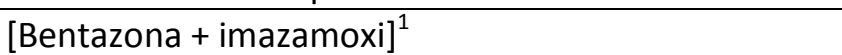 & $48,0 \mathrm{~b}$ & $6,51 \mathrm{a}$ & 95,54 a & $144.500 \mathrm{a}$ & $7,2 \mathrm{a}$ & $43,6 \mathrm{a}$ & $194,1 \mathrm{a}$ & 861,67 a \\
\hline 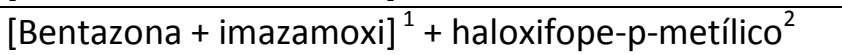 & $52,8 \mathrm{a}$ & $6,46 a$ & 89,87 a & $114.000 \mathrm{~b}$ & $7,4 a$ & $40,9 \mathrm{a}$ & 193,7 a & 830,06 a \\
\hline$[\text { Bentazona }+ \text { imazamoxi }]^{1}+$ fenoxaprope-p-etílico ${ }^{2}$ & $55,5 \mathrm{a}$ & $6,28 \mathrm{a}$ & $95,54 \mathrm{a}$ & $142.000 \mathrm{a}$ & $8,1 \mathrm{a}$ & $47,3 \mathrm{a}$ & $200,7 \mathrm{a}$ & 899,79 a \\
\hline$[\text { Bentazona }+ \text { imazamoxi }]^{1}+$ fluazifop-p-butil $^{2}$ & $49,5 b$ & $6,05 \mathrm{a}$ & $95,45 a$ & $133.500 \mathrm{a}$ & $7,9 \mathrm{a}$ & $36,1 \mathrm{a}$ & $203,5 \mathrm{a}$ & 905,04 a \\
\hline 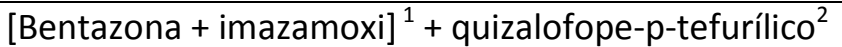 & $47,2 \mathrm{~b}$ & $6,56 \mathrm{a}$ & 75,29 a & $146.500 \mathrm{a}$ & $6,1 \mathrm{a}$ & $38,7 \mathrm{a}$ & 206,9 a & $819,21 \mathrm{a}$ \\
\hline$\left[\right.$ Bentazona + imazamoxi $^{1}+$ cletodim $^{2}$ & $46,0 \mathrm{~b}$ & $6,90 \mathrm{a}$ & 77,34 a & $147.500 \mathrm{a}$ & $6,8 \mathrm{a}$ & $42,3 \mathrm{a}$ & 207,3 a & $750,49 a$ \\
\hline 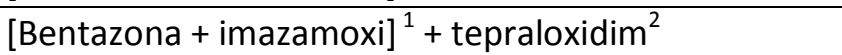 & $53,7 \mathrm{a}$ & $6,76 \mathrm{a}$ & $109,21 \mathrm{a}$ & $141.500 \mathrm{a}$ & $6,9 a$ & $39,8 \mathrm{a}$ & 194,7 a & $882,84 \mathrm{a}$ \\
\hline CV (\%) & 8,84 & 8,99 & 28,92 & 11,69 & 22,46 & 21,39 & 4,28 & 19,92 \\
\hline \multicolumn{9}{|c|}{ Ensaio 2} \\
\hline Testemunha capinada & $51,8 \mathrm{a}$ & $6,64 a$ & $114,32 \mathrm{a}$ & $150.000 \mathrm{a}$ & $7,2 \mathrm{a}$ & $45,2 \mathrm{a}$ & $201,0 \mathrm{a}$ & $942,41 \mathrm{a}$ \\
\hline Testemunha não capinada & $45,9 \mathrm{~b}$ & $6,32 \mathrm{a}$ & $74,60 \mathrm{~b}$ & $107.333 \mathrm{~b}$ & $6,5 \mathrm{a}$ & $36,9 \mathrm{~b}$ & $197,5 \mathrm{a}$ & $391,63 \mathrm{~b}$ \\
\hline 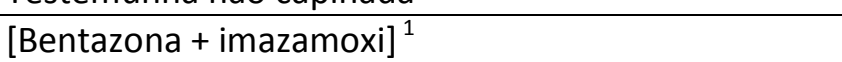 & $58,8 \mathrm{a}$ & $7,56 \mathrm{a}$ & $108,46 \mathrm{a}$ & $146.000 \mathrm{a}$ & $8,6 a$ & 56,6 a & 196,9 a & 894,97 a \\
\hline$[\text { Bentazona }+ \text { imazamoxi }]^{1}+$ haloxifope-p-metílico $^{2}$ & $50,4 \mathrm{a}$ & $6,58 \mathrm{a}$ & 111,99 a & $140.500 \mathrm{a}$ & $5,9 a$ & $44,5 \mathrm{a}$ & $197,3 \mathrm{a}$ & 935,05 a \\
\hline Bentazona + imazetapir ${ }^{1}$ & $59,0 \mathrm{a}$ & $6,63 \mathrm{a}$ & $128,95 \mathrm{a}$ & $169.000 \mathrm{a}$ & $7,6 a$ & $51,2 \mathrm{a}$ & 188,4 a & 944,19 a \\
\hline Bentazona + imazetapir $^{1}+$ haloxifope-p-metílico $^{2}$ & $57,3 \mathrm{a}$ & $7,09 a$ & $118,22 \mathrm{a}$ & $158.500 \mathrm{a}$ & $7,6 a$ & $48,2 \mathrm{a}$ & 185,8 a & 937,89 a \\
\hline Imazetapir $^{1}$ & $51,3 \mathrm{a}$ & $6,51 \mathrm{a}$ & 99,48 a & $156.500 \mathrm{a}$ & $6,5 \mathrm{a}$ & $34,1 \mathrm{~b}$ & 198,3 a & $914,31 \mathrm{a}$ \\
\hline Imazetapir $^{1}+$ haloxifope-p-metílico ${ }^{2}$ & $56,1 \mathrm{a}$ & $7,12 \mathrm{a}$ & $88,06 \mathrm{~b}$ & $139.000 \mathrm{a}$ & $8,3 \mathrm{a}$ & $51,5 \mathrm{a}$ & $194,1 \mathrm{a}$ & 945,02 a \\
\hline Etoxissulfurom + bentazona ${ }^{1}$ & $38,6 \mathrm{~b}$ & 6,13 a & $112,94 \mathrm{a}$ & $140.000 \mathrm{a}$ & $5,4 a$ & $36,9 \mathrm{~b}$ & 199,7 a & 937,89 a \\
\hline Etoxissulfurom + bentazona $^{1}+$ haloxifope-p-metílico $^{2}$ & $44,4 \mathrm{~b}$ & $6,19 \mathrm{a}$ & $76,07 \mathrm{~b}$ & $148.000 \mathrm{a}$ & $7,5 a$ & $37,4 \mathrm{~b}$ & $187,0 \mathrm{a}$ & $879,82 \mathrm{a}$ \\
\hline $\mathrm{CV}(\%)$ & 14,86 & 8,92 & 19,32 & 11,74 & 22,47 & 20,55 & 5,04 & 13,68 \\
\hline
\end{tabular}

${ }^{1}$ Herbicidas aplicados aos 13 dias após a emergência do feijoeiro. ${ }^{2}$ Herbicidas inibidores da Acetilcoenzima A carboxilase aplicados três dias após a aplicação dos demais. Médias

seguidas pelas mesmas letras são estatisticamente iguais pelo teste de Kcott-knott


Diversos fatores podem afetar o crescimento vegetativo e reprodutivo das culturas, e dessa forma, a interferência exercida por plantas daninhas, a fitointoxicação causada por alguns herbicidas e o antagonismo existente entre alguns agroquímicos, podem interferir no rendimento de plantas de feijão (ASSIS et al., 2014; TAKANO et al., 2015; MARCHIORETTO; DAL MAGRO, 2018). Parte dos resultados desta pesquisa concordam com Linhares et al. (2014) que relataram que a mistura dos herbicidas bentazona + imazamoxi não afetou as características relacionadas ao crescimento de plantas e os componentes de produção do feijãocaupi. E também com Silva et al. (2014) que concluíram que os herbicidas $S$-metolacloro, bentazona + imazamoxi, $S$-metolacloro + bentazona + imazamoxi, imazamoxi + fluazifop-pbutyl, imazetapir + fluazifop-p-butyl, bentazon + fluazifop-p-butyl, bentazona + imazamoxi + fluazifop-p-butyl e fluazifop-p-butyl foram seletivos para a cultura do feijão-caupi.

A interferência de plantas daninhas durante todo o ciclo da cultura do feijão-caupi resultou em redução da produtividade em cerca de $60 \%$.

\section{Conclusões}

A mistura bentazona + imazamoxi é seletiva ao feijoeiro cultivar BRS Guariba e promove excelente controle das plantas daninhas A. tenella, C. benghalensis e N. physaloides e controle deficiente para $E$. indica, $C$. echinatus e soja tiguera.

Imazetapir associado ou não a bentazona são seletivos ao feijoeiro cultivar BRS Guariba e promove controle moderado ou deficiente para $A$. tenella, $C$. benghalensis, E. indica, $C$. echinatus e soja voluntária. Associado a bentazona, o imazetapir possui controle excelente de $N$. physaloides.

Apesar de sintomas de fitointoxicação, o feijoeiro cultivar BRS Guariba é tolerante a associação dos herbicidas etoxissulfuron + bentazona. A mistura de etoxissulfuron + bentazona promove controle excelente de $N$. physaloides e da soja tiguera, deficiente para $A$. tenella, $E$. indica e $C$. echinatus e moderado para C. benghalensis na cultura do feijão-caupi.

Para o controle de $E$. indica e $C$. echinatus se faz necessário o uso de inibidores da ACCAse.

\section{Agradecimentos}

Ao Instituto Federal Goiano - Campus Rio Verde, pelo apoio financeiro.

\section{Referências}

ALAM. Recomendaciones sobre unificación de los sistemas de evaluación en ensayos de control de malezas. ALAM, v. 1, n. 1, p. 35-38, 1974.

ASSIS, A.C.L.P.; REIS, M.R.; PESSOA, G.D.O.; SILVA, D.V.; HAYATA, M.; DIAS, R.C.; ROCHA, B.H. Seletividade do ethoxysulfuron às culturas da soja $\mathrm{e}$ feijão. Revista Brasileira de Herbicidas, v.13, n.2, p.117-124, 2014. https://doi.org/10.7824/rbh.v13i2.278

BANDEIRA, H.F.S.; ALVES, J.M.A.; ROCHA, P.R.R.; STRUCKER, A.; TRASSATO, L.B.; JESUS VIEIRA, A. Crescimento inicial do feijão-caupi após aplicação de herbicidas em pós-emergência. Revista Brasileira de Herbicidas, v. 6, n.2, p.112-121, 2017. https://doi.org/10.7824/rbh.v16i2.503

CAMARA, F.T.; MOTA, A.M.D.; ARAÚJO NICOLAU, F.E.; PINTO, A.A.; SILVA, J.M.F. Produtividade de feijão caupi crioulo em função do espaçamento entre linhas e número de plantas por cova. Journal of Neotropical Agriculture, v.5, n.2, p.19-24, 2018. https://doi.org/10.32404/rean.v5i2.2282

CORRÊA, M.J.P.; ALVES, G.L.; ROCHA, L.G.F.; SILVA, M.R.M. Períodos de interferência de plantas daninhas na cultura do feijão caupi. Revista de Ciências Agroambientais, v.13, n.2, p.50-56, 2015.

FONTES, J.R.A.; OLIVEIRA, I.J.; GONÇALVES, J.R.P. Seletividade e eficácia de herbicidas para cultura do feijão-caupi. Revista Brasileira de Herbicidas, v.12, n.1, p.47-55, 2013. https://doi.org/10.7824/rbh.v12i1.214

FONTES, J.R.A.; OLIVEIRA, I.J.; MORAIS, R.R. Manejo de plantas daninhas na cultura do feijão-caupicontrole cultural em cultivares de portes prostrado e semiprostrado. Manaus/Itacoatiara: Embrapa Amazônia Ocidental , 2017.

FREIRE FILHO, F.R. Feijão-caupi no Brasil: produção, melhoramento genético, avanços e desafios. Teresina: Embrapa Meio-Norte, 2011.

FREITAS, F.C.L.; MEDEIROS, V.F.L.P.; GRANGEIRO, L.C.; SILVA, M.G.O.; NASCIMENTO, P.G.M.L.; NUNES, G.H. Interferência de plantas daninhas na cultura do feijão-caupi. Planta Daninha, v.27, n.2, p.241-247, $2009 . \quad$ http://dx.doi.org/10.1590/S0100$\underline{83582009000200005}$

LEITE, L.F.C.; ARAÚJO, A.S.F.; COSTA, C.D.N.; RIBEIRO, A.M.B. Nodulação e produtividade de grãos do feijão-caupi em resposta ao molibdênio. 
Revista Ciência Agronômica, v.40, n.4, p.492-497, 2009.

LINHARES, C.M.S.; FREITAS, F.C.L.; SILVA, K.S.; LIMA, M.F.P.; DOMBROSKI, J.L.D. Crescimento do feijãocaupi sob efeito dos herbicidas fomesafen e bentazon+imazamox. Revista Caatinga, v.27, n.1, p.41-49, 2014.

MANCUSO, M.A.C.; AIRES, B.C.; NEGRISOLI, E.; CORRÊA, M.R.; SORATTO, R.P. Seletividade e eficiência de herbicidas no controle de plantas daninhas na cultura do feijão-caupi. Revista Ceres, v.63, n.1. p.25-32, 2016. http://dx.doi.org/10.1590/0034-

737X201663010004

MARCHIORETTO, L.R.; DAL MAGRO, T. Efeito protetor do bentazon sobre os efeitos fitotóxicos de herbicidas inibidores de ALS em duas cultivares de feijoeiro. Revista de Ciências Agroveterinárias, v.17, n.1, p.77-82, 2018. http://dx.doi.org/10.5965/223811711712018077

MONTEIRO, M.M.S.; BASTOS, E.A.; CARDOSO, M.J.; ANDRADE JÚNIOR, A.S.; RIBEIRO, V.Q. Efeito de regimes hídricos e densidades de plantas na produção de feijão-caupi. Pesquisa Agropecuária Tropical, v.47, n.4, p.432-439, 2017.

OLIVEIRA O.M.S.; SILVA J.F.; GONÇALVES J.R.P.; KLEHM C.S. Período de convivência das plantas daninhas com cultivares de feijão-caupi em várzea no Amazonas. Planta Daninha, v.28, n.3, p.523-530, $2010 . \quad$ http://dx.doi.org/10.1590/S0100$\underline{83582010000300009}$

OLIVEIRA, F.S.; SILVA GAMA, D.R.; DOMBROSKI, J.L.D.; SILVA, D.V.; OLIVEIRA FILHO, F.S; RAMALHO NETA, T.; SOUZA, M.M. Competition between cowpea and weeds for water: Effect on plants growth. Revista Brasileira de Ciências Agrárias, v.13, n.1, e5507, 2018. http://dx.doi.org/10.5039/agraria.v13i1a5507

OLIVEIRA, R.L.; QUARESMA, C.C.F.; CASTRO, H.G.C.; LIMA, J.M.P.; MOURA, M.F.V. Determinação de umidade, cinzas e fósforo em quatro variedades de feijão caupi. Revista Química: Ciência, Tecnologia e Sociedade, v.4, n.2, p.24-32, 2015. https://doi.org/10.5151/chenpro-5erq-qan6

RIBEIRO JUNIOR, L.F.; GONÇALO, T.P.; SOUSA, B.F.; COSTA, J.L.B. Tolerância inicial de feijão-caupi a herbicidas aplicados em pré-emergência. Revista Brasileira de Herbicidas, v.17, n.3, p.603-610, 2018. https://doi.org/10.7824/rbh.v17i3.603
SÁ, F.V.D.S.; FERREIRA NETO, M.; LIMA, Y.B.D.; PAIVA, E.P.D.; GHEYI, HR.; DIAS, N.D.S. Initial development of cowpea plants under salt stress and phosphate fertilization. Revista Ambiente e Água, v.12, n.3, p.405-415, 2017. http://dx.doi.org/10.4136/ambi-agua.2070

SBCPD. Procedimentos para instalação, avaliação e análise de experimentos com herbicidas. Londrina: SBCPD, 1995.

SILVA, K.S; FREITAS, F.C.L.; SILVEIRA, L.M.; LINHARES, C.S.; CARVALHO, D.R.; LIMA, M.F.P. Eficiência de herbicidas para a cultura do feijãocaupi. Planta Daninha, v.32, n.1, p.197-205, 2014. http://dx.doi.org/10.1590/S010083582014000100022

SIMPLICIO, S.F.; GONCALVES, A.C.M. ; DUARTE, E.C.C.; BARBOSA, W.M.C.; RODRIGUES, J.P.C.S.; OLIVEIRA, B.S.; SOUSA JUNIOR, S.P. Características de crescimento e produção do feijão-caupi (Vigna unguiculata L. Walp.) sob aplicação de herbicidas. Agropecuária Técnica, v.37, n.1, p.55-62, 2016.

SOUZA LIMA, C.J.G.; OLIVEIRA, F.A.; MEDEIROS, J.F.; OLIVEIRA, M.K.T.; OLIVEIRA FILHO, A.F. Modelos matemáticos para estimativa de área foliar de feijão caupi. Revista Caatinga, v.21, n.1, p.120-127, 2008.

TEIXEIRA, I.R.; SILVA, G.C.; OLIVEIRA, J.P.R.; SILVA, A.G.; PELÁ, A. Desempenho agronômico e qualidade de sementes de cultivares de feijão-caupi na região do cerrado. Revista Ciência Agronômica, v.41, n.2, p.300-307, 2010.

VALE, J.C.; BERTINI, C.; BORÉM, A. Feijão-caupi: do plantio à colheita. 1. ed. Viçosa: Ed. UFV, 2017.

ZILLI, J.E.; SILVA NETO, M.L.; FRANÇA JÚNIOR, I.; PERIN, L.; MELO, A.D. Resposta do feijão-caupi à inoculação com estirpes de Bradyrhizobium recomendadas para a soja. Revista Brasileira de Ciência do Solo, v.35, p.739-742, 2011. 